\title{
CURRENT THEORIES OF EVOLUTION ${ }^{\text {1) }}$
}

by J. P. Lotsy.

The biologist, travelling in America, is greatly impressed by the astonishing diversity of scenery, climate and life on this wonderful continent.

Within a few days he passes from winter to summer, from humid regions to deserts, from high peaks to chasms of the amazing depth of the Grand Canyon of the Colorado, from the Giant Cacti in the desert of Arizona to the Giant Macrocystis, thrown by the waves of the Pacific on a Californian beach, from the treeless plains of Kansas and Texas to those Giants of the Forest - the Sequoia's of the Yosemite - the grandeur of which can only be felt, not described.

No less diversity is revealed, to even the casual observer, in regard to the minds of the inhabitants of this vast continent.

While there is, on the one hand, a remarkable output of first-class work in the fields of Heredity and Evolution, which has made the names of many American Scientists well known all over the world, there is another type of mind, whose reputation, I fear, will not be as enviable as that of the men just referred to. A Mr. Bryan, a Dr. Porter and a certain Mc. CANn, apparently, try to revive the times of 1859 in England, when DARWIN's book on the Origin of Species caused so much adverse comment in orthodox religious circles.

The older ones among us remember how at a meeting of the British Association for the Advancement of Science, Bishop WiLBERforce asked HUXLEY, whether he descended in the male or in the female line from a monkey, and how the Bishop received the memorable answer that HuXLEY would not have been ashamed of apes among his ancestors, but that he would have felt very much ashamed of

1) Read at the Meeting of the American Association for the Advancement of Science at Salt Lake City, Utah July 1922.

Genetica. 
an ancestor, who, speaking of a subject of which he had no accurate knowledge, played upon prejudice to evoke opposition against the results obtained by patient work and deep reflection by a high minded man and a great naturalist.

I would feel very much the same in regard to an ancestor like Mr. BRYAN, who although lacking in knowledge of even the rudiments of the doctrine of evolution, yet tries, and in one State almost succeeded, to suppress the teaching of it, or to one of the type of J. W. Porter, D. D., L. L D., who in his booklet „Evolution a Menace" states brazenly, that hybridisation can never have played a role in evolution, because, as everybody knows, mnles are sterile!

Yet, I prefer Dr. Porter to Mr. Bryan, because the dedication of his pamphlet has given me so much pleasure, as no doubt it will give you.

It reads :

"To my beloved and womanly wife, on whose brow is stamped, the likeness of Him, in whose ,image" she was created, and whose pure and noble blood is untainted by that of insects, reptile, fowl or beast."

As to the third book of this type, Mc. CANn's "God or Gorilla": the title alone suffises to reveal the coarsity of the mind of the author, who, by his publisher, is presented to us as the man "who has been plaintiff or defendant in 206 libel suits and won every one of them." Possibly the opponents of Evolution are proud of this champion, I am sure that all of us are glad that he is not on our side.

I have only referred to this kind of litterature to emphasize the fact, that whatever object we observe in nature: climates, scenery, the bodies or the minds of plauts or animals, including man, we find endless diversity. A similar diversity we meet with, when we proceed to a more detailed study of nature.

In the Natural History Museum in New York, I saw a number of scallop shells (Pecten) taken from a peck, bought in the market, arranged according to the number of their rays, showing that, among scallops also, there is considerable diversity; the naturalist, responsible for this exhibition, however, does not refer to it as to a demonstration of diversity, but speaks of variation.

Yet, there is not the slightest doubt, that what he found and 
demonstrated was diversity and nothing but diversity. Why then does be speak of variation? Because he has a creed, the firm belief that all scallops have descended from a single initial specimen, or from a pair of such and that scallops were wont to reproduce their kind faithfully, until, in some mysterious way, they changed their constitution, by a process, limited to living matter, which process was called: variation. There is, ofcourse, no doubt, that organisms do vary, that, for instance, part of the progeny of a particular kind of plants, raised under unfavorable conditions, has quite another aspect than another part, raised under favorable ones, so that the exhibit of scallop-shells in the New York Museum may illustrate variation, but this conclusion can not legitimately be drawn from the mere observation of differences, in as much as such observation is unable to reveal anything else than the existence of diversity. How easy it is to confound diversity with variation the following case, may show. A mexican shrub of the Composite family : Parthenium argentatum was considered to be highly variable. A thorough investigation by $D_{R}$. MACALLUM of Continental in Arizona has revealed the presence of more than a thousand different types within this linneon, each of which proved, on cultivation, to be perfectly constant; the supposed variability, thus proved, on proper investigation, to be mere diversity. As a matter of fact mere observation can never reveal variability. We all know that there was a time when it was considered possible to distinguish between variability and diversity by observation and registration only. If the observed differences could be arranged in such a way that they oscillated around a common mean. in other words that they gave a frequency-curve it was thought that reliable evidence of variation was obtained. The mere mentioning of the name JoHAnnsen is sufficient to remind you of the fallacy of this deduction, as you know that he showed how genotypically different types of beans, bought in the market, could be arranged in such a way that they formed an almost ideal frequency-curve.

Consequently we can observe diversity, but we have to study experimentally, whether observed deviations from the form which we consider as the type of a species (which, as a rule, means nothing but the most frequent form or even merely the first discovered form within that species) are variations or not. 
The impossibility to apply the experimental test in most cases makes phylogenetic deductions from material which we can only compare - and in the case of fossils we can do nothing else so very uncertain. All conclusions as to continuous variation or orthogenesis, based on even the finest graded series between two conspicuously different types, are mere speculations because the occurence of intermediates does not reveal their mode of origin, so that from such an occurrence the conclusion may not be drawn that the observed intermediates are transitional forms between the extreme types. Nor is it legitimate to refer to breaks in such a series of intermediates as to "missing links," because no form may ever have filled the gap which we observe. An example may illu. strate what has been said about intermediates.

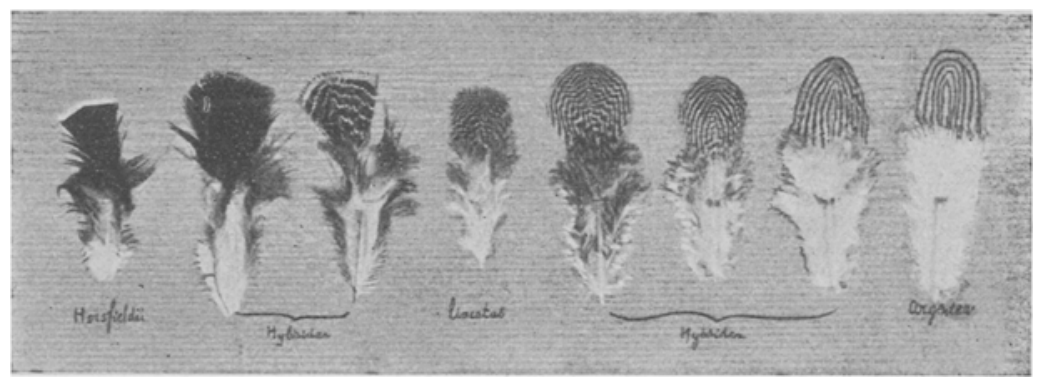

Fig. 1. Two species of Pheasants and their hybrids; from left to right: Feather of Gennaeus Horsfieldii; two feathers of hybrids $G$. Horsfieldii $\times G$.lineatus; feather of $G$.lineatus; three feathers of hybrids $G$.linealus $\times G$. argentatus; feather of $G$, argentea; all from the experiments of GHigt.

We can arrange the feathers of certain pheasants in such a way that they make a magnificent series of intermediates between Gennaeus argentatus and Gennaeus lineatus, or between the latter and Gennaeus Horsfieldii and we may feel inclined to read this series as one of transition, between the species named, revealing continuous variation or even orthogenesis. Moreover, we may collect such intermediate specimens in regions between those in which the species mentioned occur, which of course would strengthen the view that these intermediate specimens are transitions between them.

Unfortunately however, for those, who have ascribed the origin of these intermediate forms to a process of variation, continuous or orthogenetic, the members of the fine series of intermediates, 
which I am showing you (Fig. 1) have not arisen by any process of variation at all, but by hybridizing Gennaeus argentatus and lineatus with one another, while the less complete series of intermediates between lineatus and Horsfieldii has been obtained from hybrids between these latter species. These experiments have been carried out by Professor Alessandro Ghigi of Bologna, to whose kindness I owe these féathers.

It cannot be too strongly emphasized that observation can reveal nothing but diversity while the experiment must be called in, to decide the cause of the observed diversity.

LiNNAEUs, with his admirably penetrating mind saw this already, but, unfortunately, did not act up to the principle he himself enunciated. Within his species he did distinguish two kinds of varieties: varietates levissimae and varietates tout court. The first, which now we would call modifications, did not, according to his view, concern the systematist because they are of a merely transient nature: varietates levissimae non curat botanicus, the latter, on the other hand, deserve all consideration: varietates attente inspiciantur, because they transmit their peculiarities to their progeny. As an example of varietates levissimae he gives different plants modified by wind, drought etc; as one of varietates: the different forms of cabbages, such as green cabbages, red cabbages, Brussels sprouts etc., all belonging to his species Brassica oleracea, which came true to seed.

LINNAEUS consequently rightly distinguished between non-transmittable varietates levissimae, our modifications, and transmittable varietates.

The giving of such similar names to so fundamentally different categories of individuals was, of course, apt to cause confusion and has caused it, even in LinNaEus' mind, to such an extent that - forgetting the distinction he himself had made - we find him speaking of a form „mutata a causa accidentali, caloris, ventis etc. as of a varietas, while, of course, he should have referred to it as to a varietas levissima. So it came about that the distinction between transmittable and non transmittable variability was forgotten and that all, merely observed, deviations from the supposedly typical individuals within a linneon were called varieties, while of course the observation of such differences within a linneon or 
Linnean species only revealed diversity within, but, by no means, variability of that species.

That LinNaEus forgot his own distinction between varietates levissimae and varietates is psychologically easily understood. We all have a tendency to move away from unpleasant facts, and the existence of diversity within his species - supposed to represent the immutable created units of nature - was of course atterly repugnant to LINNAEUS.

The consequence of this forgetfulness on the part of so exclusive an authority as LiNNAEUs then was, bas become disastrous, because from now on diversity and modification became known under the same name: variability. This mistake became tenfold worse when LAMARCK claimed that modifications tended to become transmittable, provided that the agents which caused them were but allowed a sufficient time to act.

From that moment on, all diversity within the Linnean species was practically ascribed to variability, caused in the last instance by nurture, or, as is more frequently said, by stimuli from the external world.

That is the view, not only of LAMARCK, but of DARWIN also, who towards the end of his life, on July 19, 1881 (DARwIN died April 19, 1882), wrote to K. SEMPER: "I still must believe that changed conditions give the impulse to variability, but that they act in most cases in a very indirect manner. But as I said it is a most perplexing problem."

Or, no attentive reader of DARwIN's works can escape the conclusion that each case of variation which he mentions, is either mere diversity "within a group which he considered to be a species - a term which he has never defined - or segregation from heterozy. gotes, and none of you here present - I am sure - would accept a single instance of variability mentioned by DARWIN; as conclusive evidence of the existence of variation, at the present moment.

The conception of transmittable variability - though born as a mistake by the confusion of diversity and variability - had however entered the domain of natural science and, apparently, had come to stay.

The belief in its existence became even so firmly established, that from the appearance of DARwIN's Origin in 1859 until about 
the year 1900 experiments on the subject of variability were very scarce (a notable exception was H. Hoffmans), while there were endless discussions as to the kind of variability causing evolution: Lamarckian or Darwinian, continuous or discontinuous (sporting), allsided or orthogenetic etc.

Even BATESON, who in his book on meristic variation made a thorough study of diversity, could not liberate himself from the belief that variation could be observed, while it can, of course, only be tested by experiment.

The one who first saw this clearly was not a botanist, but an amateur, a manufacturer of silk goods at Lyon: Alexis JorDan, who put the question at issue correctly: I see diversity within the Linnean species, this diversity is hypothetically called variation, I shall test this hypothesis and see whether it is well or ill-founded. We all know that he found it ill-founded, that he could prove that all morphologically distinguishable types within the Linnean species Draba verna, more than 300 in all, come perfectly true, when grown from guarded seed, or, in other words, that Draba verna was not a highly variable species, a variable unit, but no unit at all; it turned out to be a collection of different units, in regard to which the Linnean species had the rank of a genus.

JORDAN, having moreover to his satisfaction, shown that these smaller units did not vary in a transmittable way, but were subject to modification only, called these units, discovered by him, which he supposed to be immutable: petites espèces, mikrospecies.

This was unfortunate, then by so doing, he sanctioned, to a certain extent, the Linnean species-concept and gave the impression that his units were of less worth. He should boldly have called his constant forms species, because the orthodox Linnean speciesconcept is the pure line concept and nothing else, and JoRDaN's mikrospecies were the first experimentally tested pure lines.

The fact that JoHannsen could show, by means of modern methods, many years later, that within morphologically similar forms, still smaller pure lines can be distinguished, does not do away. with the fact, that it was JORDAN, who first logically applied the pure line principle, to wit: to sow the guarded seed of a single type and that it was he, who, from the results obtained, drew the conclusion that such pure lines were immutable. 
This conception of the immutability of JoRDan's species or of pure lines, or, as we would now express it, the immutability of the homozygous as well as of the haploid genotype, was of course utterly distastefull to evolutionists, who could conceive of no other possibility of evolution, than by some process of variability and, as a consequence, JORDAN's splendid work was disregarded.

All the same, I feel inclined to believe that JORDAN was right, that the pure genotype is immutable; anyhow there is no doubt, that the cases of transmittable variability mentioned by LAMARck and DARWIN were nothing of the kind, but were either modifications, wrongly supposed to be able to become transmittable or diversities within groups of individuals, wrongly supposed to be homogenous or, again, segregates from heterozygotes, wrongly supposed to be homozygotes.

The new period of evolution begins with DE VRIES.

JoRDAN's work was, as we saw, disregarded; the existence of transmittable variability had become a dogma, and in stead of experimenting one limited ones efforts to discussing which kind of variability was the cause of evolution.

We all know that DE VRIEs claimed to have proved the existence of mutation in the case of Oenothera Lamarckiana.

It is a curious fact that this claim, at the time it -was presented, was very generally granted, because DE VRIES himself stated, that he had never possessed a Lamarckiana which did not throw the aberrant forms, which he called mutants, so that all he actually proved - a very important fact - is that $O$. Lamarckiana was a type of plant which throws aberrant forms in every generation. This of course made the mutational nature of these aberrant forms purely hypothetical and forced DE VRIES to place their origin in the uncontrollable past.

The very curious behaviour of $O$. Lamarckiana, discovered by DE VRIES, has not yet been entirely elucidated; different investigators offer different explanations but all agree, and even DE VRIES has admitted, that the Lamarckiana's, which we actually know are heterozygotes, while it has also been proved that a considerable part of DE VRIES' socalled mutants are certainly not due to mutation but to irregular chromosome distribution.

Not all however; and this puts us under the obligation to consider 
the important question whettrer the mere fact of heterozygosity excludes the possibility of the obtention of definite proof of the existence of mutation.

To answer this question we must have a clear understanding of what is meant by mutation.

The mutation-concept of DE VRIES is based on an assumption, on the assumption that an organism consists of a large number of very small living particles, of mutually independant organoids, his pangens, capable of multiplication by fission.

The conception of variability - derived, as we have seen from a confusion of diversity with variability - was, by DE VRIES, carried forward to these pangenes. This had the great advantage to do away with all confusion of variability with diversity, the question now became a very definite one: are genes, or to put the question sharper still, is a single gene variable in such a way that its constitution is permanently changed?

Such a change is conceivable, both in a homozygous and in a heterozygous organism, I can even imagine the possibility of obtaining proof of it - if the assumption of the existence of such genes should prove to have hit the mark - in the case of a heterozygous organism. so that one is not justified in denying offhand the possibility of proof of mutation of this kind from heterozygous beings.

At the present time however, the existence of living pangenes is nothing but a hypothesis; which is by no means generally accepted; JOHANNSEN even does not hesitate to call its assumption absurd:

"Viele Zytologen sind - wie es WeIsmanN und andere waren geneigt an "organoide Gebilde zu denken, Gebilde die in den Zellstructuren (Chromosomen, Chromatinkernen) localisirt sein sollen. Vor dieser Auffassung muss entschieden gewarnt werden. Die Genen als selbständige „lebende" Elemente auf zu fassen wäre ganz ungereimt, auch die Annahme einer Selbständigkeit in dem Sinne, dass ein Gen „für sich” im Stande wäre, irgend etwas zu realisiren ist bis jetzt unbegründet und fusst offenbar nur in morphologischen Auffassungen einer organoiden Natur dieser Einheiten. Der GesammtGenotypus bestimmt die Erscheinungen von welchen hier die Rede ist." 
In this, I fully agree with JoHANNSEN.

The development of an eggcell to an individual with its many and manyfold organs is one of the most amazing processes, of which we know, the many "Entwicklungsmechanische Studien" notwithstanding, practically nothing. The reason is that such studies can reveal, at the best, the mechanism but not the underlying causes of development.

It seems to me impossible to consider morphogenesis as the result of a mere aggregation of mutually independent particles, it must ultimately depend on and result from the molecular structure of the eggcell.

As a working hypothesis the gene-hypothesis is doubtless a valuable one, but it is utterly unable to give us an insight in what really happens, the conception is altogether too coarse, I would almost say, too naive for this purpose.

An organism is not a mere aggregate of a limited number of mutually independent living particles, it is an entity and life is a property of the whole or of considerable parts of the whole not of separate geres, just as the characters of an organism are characters of the whole.

The fact that the same character, f.i. blue flower-color, is common to a great many different plants by no means warrants the conclusion that it is caused in all those cases by an identical gene. The blue color is caused in all those organisms by particular molecular structures, which need not be identical at all, but all of which - different as they may be and doubtless are - break the light in such a way that our eye receives the impression which we call blue.

Coppersulphate is blue, the cloudless skye is blue, cobaltglass is blue, some silk goods are blue, yet nobody thinks of ascribing the blue color of all these objects to the presence of an identical "gen" in all of them. Nor can we say that in coppersulphate f.i. the blue color is caused by any particular constitnent of it, such a conclusion might be drawn if the removal of one constituent only, say of the copper present in it, caused the blue color to disappear, but coppersulphate looses its color not only after removal of the copper from it, but also after removal of the sulphur, of the oxygen or even of the mere crystallwater it contains, so that the character 
blue is not caused by one of its constituents but by the interaction of them all.

This illustrates perhaps better than any other case I can think of, the fundamental difference between the point of view of the gene-conception based on mere morphological consideration and the physico-chemical conception based on physiological considerations. Whatever the structure of an organism may be it certainly is the seat of very complicated chemical interactions, which, the persistance of organisms of a certain kind, during long geological periods, proves it, are in all essentials independent from such changes in the external circumstances as happen to occur in nature.

To assume that these interactions take place in essentially the same way, generation after generation, and then should suddenly change, without any apparent cause, seems to me an unwarranted assumption which comes dangerously near to the doctrine of creation.

And here we have reached the point where the morphological (gene) and the physiological (physico-chemical) conception can never agree as to the significance of changes occurring in heterozygous organisms.

While the morphologists may, by accumulation of considerable circumstantial evidence, such as for instance that obtained by MoRGaN in the case of Drosophila, even if such evidence is obtained from a heterozygous organism, feel finally convinced, that a gene has mutated, the physiologist, in the sense as explained above, can never ascribe mutational value to a change obtained from heterozygous stock, no matter how wide a meaning one is willing to give to this term short of a change caused by the insertion of something previously foreign to the slock in question.

For him, just as for the chemist, purity of the initial material is a conditio sine qua non for the obtention of definite proof of the existence of mutation.

In heterozygous organisms the possibilities of interaction of chromosomes differing in structure may simulate mutation, may cause a change in a particular molecular group situated at a particular point in one of the chromosomes, for, to $\mathrm{my}$ mind also there is no doubt that chromosomes and cytoplasm both have a definite molecular structure, but this is not mutation but simply chemical interaction between two objects capable to enter into such an action with one another. Such a change could only then be interpreted as a mutation 
in a sense akin to that of DE VRIES, if the two chromosomes in question possessed identical structure.

Taking up the historical thread again, we must now ask how it happened, that DE VRIEs' deductions from his Oenothera-observations were so readily accepted, notwithstanding the fact, that he himself stated not to have caused $O$. Lamarchiana to mutate but merely to have observed the throwing of aberrant forms by it.

It seems to me that the reason of this ready acceptance, was the great relief we all felt, that that elusive damsel transmittable variability, in whose existence we all believed, seemed finally to have been entrapped.

And even, at the present moment, the belief in the existence of dame transmittable variability, is so great, that she is still diligently pursued.

I shall not refer to all cases of supposed mutation found in the literature, nor could $I$, where the time at my disposal is so short for so vast a subject as I was asked to present to you, but shall limit my remarks to that most ingeniously worked out organism Drosophila ampelophila. Nor shall I discuss here the question of crossing over, so intimately connected with MoRgan's acceptance of mutation, but only call your attention to the, it seems to me, significant fact, that all so called mutants obtained by Morgan, except one, were obtained from wild stock.

In other words: all forms obtained by him from the wild stock, except one, proved to be constant in regard to the particular character in which they differed from the wild stock.

From this, to me, the most logical conclusion seems to be, that the wild stock which throws the supposed mutants is impure, and that, after purification, the phenomerion of mutation ceases.

It is true, that sometimes a deviating form appeared among the mutants, but of these Morgan himself says:

"It would be a point of capital importance, if it could be determined beyond doubt that at times recessive mutant genes change back to the original (wild type) gene, or even if a recessive gene could mutate to a dominant one. The appearance of the wild type in a pure culture of a mutant race can be accepted as good evidence of such a change only, when every possibility of contamination by the wild type is excluded and this is difficult to regulate. In our 
cultures we have come across such cases, but have not ventured to exploit them, since wild type flies are always present in the laboratory and hence the discovered form may have arisen through contamination. Thus even when a red eyed yellow fly appeared in the white-eyed yellow stock, there is the barest chance that a yellow red-eyed fly or an egg of such a fly had somehow gotten into the stock."

This is admirably sincere, but justifies my position that positive proof of the existence of mutation has not yet been obtained. But even supposing, for argument's sake, that MORGAN's aberrant forms were mutants, then still they would have no evolutionary value, as Morgan himself says that he does not consider them large enough to transgress the limit of the group of individuals known to taxonomists as Drosophila ampelophila or, more recently, as D. melanogaster.

As a matter of fact different eyecolors, differences in hoariness and other such minor differences, or defects such as crumpled or abortive wings are all diversities observed within every Linnean species and to them any particular value in evolution, can hardly be ascribed. Whenever they appear, nature - Drosophila itself shows it - very soon succeeds in eliminating most of them.

In this respect MoRGaN's mutants differ considerably from those of DE VRIES; the latter obtained aberrant forms which did transgress the limits of Oenothera Lamarckiana, so that I cannot escape the feeling, that while the hunt of dame variability started with the pursuit of big game, it has gradually dwindled to that of game decreasing perpetually in size, so that, while gone out to hunt elephants, some of us now express satisfaction at the death of a mouse! The reason for this, it seems to me, is the continuation of the belief that the diversity which we observe in nature, can be explained in one way only, to wit on the assumption of the existence of some kind of transmittable variability. Still it has long been known, that diversity, can be caused in another way, to wit by:

\section{Hybridisation.}

But this effect of hybridisation has, for a long time, been explained away by assuming that the diversity observed after hybridization, 
was not caused directly by it but indirectly only in as much as hybridization merely stimulated that mysterious property of living matter: variability. After MENDEL's classic work, this view is however untenable. MENDEL proved, beyond doubt, that the direct cause of the diversity after crossing was hybritization and nothing but hybridization. But MENDEL's work remained unnoticed until almost forty years after its publication. This was not due, as is frequently supposed, to it having escaped the notice of men, who should be considered to be capable judges, because we now know that Mendel's work was known to Focke, Galton, Kerner von Marilaun and Nägeli.

What then was the cause of the disregard of MendeL's work?

In the first place, that it was expressed in mathematical terms, which could not be interpreted biologically at a time when nothing was known about the existence of chromosomes. Consequently this mathematical accuracy made so little impression, on even so competent a judge in matters of hybridization as FOCKE, that he merely states that MENDEL obtained essentially the same results as KNIGHT long before him, but that he believed to have found constant numerical relations between the different types obtained.

In the second place that MENDEL had the misfortune to run up against Kerner von MARILAUN and Nägeli, two authorities, who both were convinced to have obtained conclusive evidence that specieshybrids were constant, so that MENDEL's results obtained from crosses of gardenpeas, even, if correct, could not have any general bearing.

Moreover MENDEL's not being a biologist, has probably played a role also in the disregard of his work. NäGELI's disregard at least can hardly be explained in any other way than by assuming distrust of results obtained by an inmate of an out of the way monastery, of whom nobody had previously heard. Yet MENDEL had sent to NäGELI a number of packages of his hybrid seeds with precise predictions as to the characters of the plants to be raised from them. NäGEL, unfortunately, trusted the sowing of these important seeds to one of his gardeners and apparently took very little further notice of them. He had too much evidence, which to him seemed to be conclusive, that the hybrids he was best acquainted with: those of Hieracia were constant. 
We now know that not MENDEL, but Nägeli was deceived, that his Hieracia-hybrids owed their apparent constancy to apogamy, and that the law of segregation discovered by MENDEL was not limited to hybrids between so called varieties only, but extended to at least some species-hybrids.

Not however to all; evidently mendelian segregation - depending, as it does, on a regular interchange of the members of a pair of chromosomes - can apply fully only to hybrids between forms whose number of chromosomes is equal.

Other kinds of hybrids must exist when formś, differing in chromosomenumbers are crossed and such have actually come to light. Täcкholm, and simultaneously and independantly from him, Miss Blackburn and.Dr. Harrison have shown that several Rosae are very peculiar hybrids of this kind, so that TäcKHOLM could even show that nearly all the Rosae, growing spontaneously in Europe, North Africa and Western Asia, which up to the time of his investigation, were all considered as good species, are, in fact, very ancient hybrids of a very peculiar kind. I will illustrate this by one example. The ordinary Rosa canina of Europe possesses 35 chromosomes, 14 of these are arranged in pairs, 21 are single. Rosa canina therefore possesses 7 hivalent chromosomes and 21 univalent ones, or, easier expressed, in BLAKESLEE's terminology; 7 disomes and 21 singles.

The divisions in the pollen mothercells occur in such a way that the four ordinary microspores contain 7 chromosomes, derived from the disomes and but a few or none of the singles. All the other microspores arisen from the pollen mothercell get derivatives from the singles only and degenerate. This is the cause of the large amount of abortive pollen in the wild Rosae. In the makrospores the reduction usually takes place in such a way that the eggcells obtain 28 chromosomes, 7 derived from the disomes and all of the 21 singles. By selffertilisation the original number of 35,7 disomes and 21 singles, will therefore be restored in all cases in which pollengrains with only 7 chromosomes, derived from the disomes, are involved. In thoses cases in which pollengrains with a larger number of chromosomes are involved, the number of chromosomes would of course be larger than 35 . There is however no necessity to assume that the latter actually ever are involved, as it is not at all 
improbable that pollengrains with more than 7 chromosomes do not sprout, because v. Overeem found in the case of triploid Oenothera's that, although pollen with all chromosomenumbers between 7 and 14 was formed, only such as contained either 7 or 14 chromosomes was able to fertilise the eggcells.

Selffertilisation however is rare in the Rosae; in most cases they reproduce apomictally - possibly from nucellar buds, how is not yet clear - which of course contain, as all vegetative tissue 35 chromosomes, so that the greater part of the Rosae of Europe are very ancient $\mathrm{F}_{1}$ hybrids, arisen thousands of years ago, and conserved as such by apomictal reproduction. A certain amount of diversity of them can of course be caused by selffertilisation as the 7 disomes allow mendelian segregation. TäcKHOLM himself assumes for part of the diversity vegetative mutation. He says:

"The enormous polymorphy characterising the section Caninae might, to a large extent, be ascribed to this obvious hybridism. However mutation phenomena have no doubt contributed to the polymorphy. In this case, the mutations must be vegetative, produced in apomictal stocks. Matsson (Svensk Bot. Tidskr. 1912) has in a sowings of tomentosa* subcristata found some forms differing from the mother. The flowers had not been castrated. Nevertheless, that one of these forms which I examined, probably was not produced in a sexual way, is evident from the chromosomeset being quite the same as that of the investigated tomentosaforms representing the $\mathrm{F}_{1}$-type $(7$ gemini and 21 unpaired chromosomes).

Of course the possibility of mutation exists - as remarked before in heterozygous forms also - but the evidence for it must be very much better founded than the one case, here mentioned: a deviating form obtained from a not castrated heterozygous plant, which plant certainly produced pollengrains with 7 chromosomes, (even if it produced viable ones with a higher number) so that the cytological evidence does not at all exclude the possibility of selffertilisation.

Hybrids between a Rosa canina with 28 chromosomes and another species with 7 chromosomes in its pollen, can of course, if selffertilised, segregate as far as the chromosomes which enter into pairs with one another are concerned, but will possess all 
those characters of the mother, which are caused by the 21 singles, which are derived from that mother only, they therefore are segregating hybrids, which all have some maternal characters in common.

Nor are the Rosae the only kind of not purely mendelian hybrids. Among the Oenotherae van OVEREEM has brought to light the peculiar fact that semigigas-forms, triploid forms, can simulate mendelian segregation to an astonishing degree, and I can fully confirm this from my own cultures. The explanation is the following. These triploids which posses 21 chromosomes distribute their chromosomes during the reduction-division in the makrospore mothercells in one of the four following ways: $\frac{14}{7} ; \frac{13}{8} ; \frac{12}{9}: \frac{11}{10}$, so that eggeells with $7,8,9,10,11,12,13$ and 14 chromosomes are formed, all of which are viable; the reduction division in the mikrospore mothercells takes place in the same way, but only those pollengrains which contain either 7 or 14 chromosomes are able to cause fertilisation.

The children consequently form a motley crowd, due to their different chromosome numbers, depending on the kinds of eggcells and the kinds of pollen combining with one another, as the following tabulation shows :

$$
\begin{aligned}
\text { eggcels pollen } & \begin{array}{c}
\text { somatic cells } \\
\text { of child }
\end{array} \\
7+7 & =14 \\
8+7 & =15 \\
9+7 & =16 \\
10+7 & =17 \\
11+7 & =18 \\
12+7 & =19 \\
13+7 & =20 \\
14+7 & =21 \\
7+14 & =21 \\
8+14 & =22 \\
9+14 & =23 \\
10+14 & =24 \\
11+14 & =25 \\
12+14 & =26 \\
13+14 & =27 \\
14+14 & =28
\end{aligned}
$$

Genetica. 
The result therefore simulates mendelian segregation, while the real cause of the diversity is unequal chromosomedistribution. The most peculiar kind of hybrids discovered so far however, is that of some sugarcane hybrids as described by Bremer. A cross of a gamete of Saccharum officinarum with 40 chromosomes with one of Saccharum spontaneum with 56 chromosomes gives a hybrid with 136 chromosomes instead of one with 96 chromosomes as one would have every right to expect. This curious result is caused by a longitudinal splitting of each of the 40 officinarum chromosomes previous to pairing, so that 80 officinarum chromosomes meet 56 spontaneum chromosomes, which gives a total of 136 . The actual pairing which subsequently occurs leaves no singles so that probably 56 officinarum chromosomes pair with 56 spontaneum chromosomes, while the rest of the officinarum chromosomes; twenty-four in all, pair with one another. We consequently get 56 hybrid disomes and 12 pseudo-hybrid disomes in the zygote.

This fact, that chromosomes can split longitudinally, previous to pairing with others, has considerable theoretical importance in connection with WINGE's hypothesis of the derivation of the individual chromosomes of a particular set from different sources, by a hypothetical process which he calls indirect chromosome-binding. This process is imagined to take place in the way indicated on p. 403. Fig. 2. 


$x=\quad$\begin{tabular}{ccccc} 
A & $\mathrm{B}^{2}$ & $\mathrm{G}$ & $\begin{array}{c}\text { chromosome- } \\
\text { number }\end{array}$ \\
\hline
\end{tabular}

The primary zygote $A \times$ B receives:

After longitudinal splitting of these (indirect chro. mosome-binding) we find in the zygote $\mathrm{A} \times \mathrm{B} \quad 2 \times 9 \mathrm{a}+2 \times 9 \mathrm{~b}$

The gametes, formed by the plant developped from the zygote $A \times B$ will con. sequently obtain :

The primary zygote $\mathrm{D} \times$ $\mathrm{C}$ then receives $9 a+9 b+9 c$

After longitudinal splitting we find in the zygote $\mathrm{D} \times \mathrm{C}$

$2 \times 9 a+2 \times 9 b+2 \times 9 c$

After reduction in $\mathrm{D} \times \mathrm{C}$ the gametes obtain:

Fig. 2. Indirect chromosome binding after Winge. 
This new species $\mathrm{E}$, although a homozygote, has nevertheless derived its chromosomes from three different sources and consequently is a hybrid, so that even the pure line is not above the suspicion of being of a hybrid nature.

If this hypothesis of WINGE should prove to be correct - and the Saccharum case points that way - it would of course emphasize the great role which hybridization has played in evolution.

No doubt WINGE's hypothesis very nicely explains the series of chromosome numbers within such genera in which each species differs from the preceding one by the so called cardinal number as $f . i$. in the case of Chrysanthemum:

$\begin{array}{clr}\text { Chrysanthemum coronarium } & 9 \\ , & \text { leucanthemum } & 18 \\ " & \text { morifolium } & 27 \\ \text { " } & \text { Decaisneanum } & 36\end{array}$

Another fact which speaks in favor of WINGE's hypothesis is the occurrence of pairs of chromosomes of different shape in a particular set as $f$. $i$. in the case of BlaKesLeE's Datura stramonium.

\begin{tabular}{lcc} 
& haploid & diploid \\
extra Large & $1 \mathrm{~L}$ & $2 \mathrm{~L}$ \\
large & $4 \mathrm{l}$ & 81 \\
large Medium & $3 \mathrm{M}$ & $6 \mathrm{M}$ \\
small medium & $2 \mathrm{~m}$ & $4 \mathrm{~m}$ \\
small & $1 \mathrm{~S}$ & $2 \mathrm{~S}$ \\
extra small & $1 \mathrm{~s}$ & $2 \mathrm{~s}$ \\
\cline { 2 - 3 } & 12 & 24
\end{tabular}

Or in that of the three pairs of Drosophila, which differ so conspicuously from one another that one might very well imagine them to have been derived from three different sources.

We consequently see that even a pure line is not above the suspicion of hybridity, that it may have derived its chromosomes from different sources, so that we are only beginning to realise how much hybridization, besides mendelian one, may be going on in nature.

What then is the

\section{Cause of Evolution.}

Although diversity was the actual starting-point of DARWIN's Selectiontheory, all of us were so thoroughly convinced of the necessity 
to apply to variability to explain the existence of this diversity, that even MENDEL's work was not able to lead us away from the road of variability.

I well remember how on a walk during a beantiful summerday in the Thuringian mountains, now some 10 years ago, the idea forced itself upon me: transmittable variability does not exist, all what has been described as such was either diversity within a group of individuals, erroneously considered to be of the same genotvpe, or segregation from heterozygotes, erroneously considered to be homozygous.

Nobody is responsible for his thoughts, nor deserves either credit or blame for them, but it is the duty of the scientist to follow them up and to test their value. This $I$ have done ever since.

At the time the thought occurred to me, a notable objection offered itself at once: varieties were supposed to differ fundamentally from species. Hybrids between varieties were generally supposed to segregate; such between species to be constant.

Yet, Correns, experiments with Mirabilis and Baur's and my own with Antirrhinum had already shown that this could not be a general rule and we now know, that we cannot distinguish varieties from species by crossing.

What then, if transmittale variability should not exist, if the genotype were immutable by itself, could be the cause of change and consequently of Evolution?

The remarkable diversity which the $F_{2}$ of a cross between Antirrhinum majus and A. glutinosum showed, induced me to consider hybridization as the cause of change and made me put forward the theory of evolution by means of hybridization.

That the diversity so obtainable is enormous and far surpassed anything that had ever been imagined on a basis of variability there is no doubt. That the simultaneous production of so large a number of different forms offered a much better chance to natural selection than a few sports could possibly do, there could be no doubt either, while it had already been proved by $D E$ VRIES that the so called continuous or fluctuating variations were nothing but modifications. I therefore felt and still feel, that if DARWIN had known of the great diversity caused by a cross, he would certainly have considered these diverse forms, arisen simul- 
taneously, as admirable material for his theory of the origin of species by natural selection.

The proof of the pudding however is in the eating and I cannot help feeling, that the pudding served to us, since I first ventured to publish my theory, tastes strongly after hybridization.

While DE VRIEs in his mutation-theory predicted that the cause of the polymorphy in Oenothera, in Draba verna, in Viola and in Helianthemum, as well as the nebulae of the older systematists in Rubus, Hieracium, Rosa and Salix would prove to be due to mutation, we now know that in all these cases, as far as examined and this has been the case with all of them expect Helianthemum even those who are yet inclined to ascribe part of that polymorphy to mutation, must admit that hybridization is responsible for by far the greater part of it, while I myself do not think that there is any proof for any influence of mutation in any of these cases.

There is another group of plants which is the despair of taxonomists: the Cacti and I was much gratified to see, during my stay at Tucson in Arizona, that in their polymorphy hybridization also, to say the least, has played a considerable role.

Not only could MAC Dougal show that hybrids between Cacti segregate, but he could also show that many at least of the wild Cacti are heterozygous to such a degree that he could not use, certain Echinocerei for instance, for his experiments to change the plasmatic constitution by injection. Moreover there are a number of presumably wild hybrids known among the Cacti, as was assured to me both by Prof. Thornber, the authority on the vegetation of the Arizona desert, and by MAC Dougal and the latter's proof of the heterozyosity of wild Cacti whose hybrid nature was not suspected, leaves no doubt that this assumption is correct.

What is more important still, is the fact that MAC Dougal could show, by observations running over a number of years, that the highly remarkable diversity in flower color in the case of Opuntia versicolor, running from pale yellow, almost white, to dark yellow, through pink, bordeaux-red of all shades to deep bluish red, is not variable at all, but typical for each individual. Now this diversity in color is exactly what we would expect to to arise by segregation after a cross and as these Cacti repro- 
duce themselves mainly by broken off branches, in other words asexually, it is evident that it was this asexual mode of reproduction which preserved the diversity which was the result of crossing. I have no doubt that several of these forms will prove to be heterozygous and am looking forward to this being tested.

The behaviour of plants, which have been multiplied in some asexual way, for a longer or shorter time, is of course a splendid test as to their mode of origin. We all know, that when we sow the guarded seeds of tulips, hyacinths, plums, pears etc, and, as I have recently seen in Riverside, of Citrus also, we get a motley crowd, showing that all these domestic products are hybrids, and as there is every reason to believe - as DARWIN rightly insists upon - that new forms arise in nature in a similar way as under domestication, this fact again speaks in favor of hybridization being the cause of evolution.

This origin by means of hybridization of our domestic plants may probably be extended to most of our domestic animals also. Mr. Houwink's experiments in Meppel tend to show that at least three species of wild fowl, to wit Gallus bankiva, Sonnerati and furcatus have taken part in the formation of our domestic poultry, as he was able to show that hybrids between them are perfectly fertile, while Prof. GHigi of Bologna has shown, that probably at least two species: to wit Columba livia and Columba leuconota have taken part in the formation of our domestic pigeons.

That, also in nature, hybridization between animals is much more common than was suspected and that many so called species of wild animals are heterozygous, has been shown by GERould in the case of the alfalfa butterfly as well as in that of various other American insects and birds and by GHIGI in the case of the pheasants of the Himalaya, in that of various species of birds around the Mediterranean and in that of African species of Numida. The Numida-case, the case of the guinea-fowl is especially interesting 'because DARWIN cites it as a case of an animal, which notwithstanding its transportation from an arid African habitat to a humid English one, did not „vary”.

Ghigi could prove that it does vary in the Darwinian sense in its native country, but only in those regions where it comes into 
contact with another Numida-species and hybridizes with it; its so called varieties therefore are, just as the varieties of so many New England Violae, as shown by BRAINERD, alterations caused by crossing.

Taking all in all, I have no doubt, that hybridization has been and still is an important factor of evolution.

Some objections may occur to you to accept it as the only cause and I myself do not think that it explains all diversity.

Allow me to consider first the objections which have come to my knowledge and then to explain at which point, to my way of thinking, the influence of hybridisation stops.

The first objection which naturally presents itself, is that deviations have been observed in pure cultures from organisms, such as fungi and bacteria, which multiply asexually only.

A case which appeared especially convincing was a form of Botrytis cinerea with colorless sclerotia obtained from a single spore strain of Botrytis cinerea with normal black sclerotia by BRIERLY and which was, at first, described by him as a mutation. Aferwards however BRIERLY considered the question whether a single strain culture in the case of multinuclear spores, such as Botrytis possesses, is a guarantee of purity and concluded that it was not.

Referring to Burgefrs crosses of various forms of Phycomyces nitens, BrIERLy says:

"In the asexual form of reproduction spores are delimited within sporangial heads into which there have passed an indefinite number of nuclei. The multinucleate spores germinate and reproduce the coenocytic mycelium. If, therefore, the original hyphae are genetically impure, this condition will be maintained in all succeeding generations, for the sporangiospores merely reproduce the genetic condition of the hyphae which give rise to sporangia. Opportunity for genetic contamination occurs at sexual reproduction, for this process is merely a fusion of two multinucleate gametes to form a, multinucleate zygospore, which on germination gives rise to a coenocytic mycelium containing nuclei of both parental strains. There will be an equal chance for both types of nuclei to pass into the sporangia and be included in the multinucleate spores. A single-spore strain may thus be heterocaryotic. If now this form at sexual maturity fuses with a third form, and so on, the genotype 
of any particular isolation may be extremely complex. As, moreover, the sporangiospores are delimited and the walls of the zygogametes laid down without any apparent regard either to the conditon, the number, or the position of the nuclei they separate, there is no absolute surety that two single-spore strains derived from an original single-spore strain will have the same genotype." After discussing some other cases he continues:

"These considerations applied to the fungus Botrytis cinerea throw an entirely new light upon the value to be attached to the colourless strain. Botrytis cinerea possesses a multicellular mycelium, each cell of which contains many nuclei. The conidiophores are multinucleate and a small but indefinite number of nuclei pass into each conidium. Throughout the whole of the vegetative and reproductive mycelium the septa are laid down by a diaphragm-like growth from the hyphal walls, irrespective of the number or condition of the auclei thus separated. Each conidium therefore merely reproduces the genetic constitution of the original cell of the mycelium in which its conidiophore arose. Many thousands of such asexual generations, would therefore, not alter the genetic constitution of the organism, and there is no sexual process. The possibility of genetic contamination is brought about by the occurrence of hyphal anastomoses. In the extremely rare chance of a fertile conidiophore arising from a cell contaminated by the nuclei or cytoplasm of a genotypically different individual lies, I believe, the explanation of the colorless form of Botrytis described. While this possibility exists, it is more consonant with the principles of scientific methodology to accept this interpretation than to formulate a mutational hypothesis of the origin of the aberrant strain."

In the case of bacteria, we know so little of the cytology that a proper discussion is not possible, but it is rather a suggestive fact that from different sides sexual reproduction is now claimed to occur among bacteria and that acase is known in which the altered form constantly gives rise to two types of colonies, one similar to the obvious parent and one like itself, the former breeding true, the other later again splitting off the former, a behaviour like that of a hybrid, splitting off recessives.

As to Protozoa we know so little as yet about the significance of their mikro- and makronuclei in heredity that no conclusions 
drawn from them can have decisive weight. JENNings himself admits that the possibility of sexual unions, and consequently of hybridization is not excluded in his experiments with Rhizopoda.

A more serious objection could, at first sight, be derived from the great diversity among Flagellate-groups like the Peridineae, which reproduce, as far as we know, asexually only. In the first place however, no "mutations" as far as I know have been described in this group, in the second place we must not forget that very much simpler Flagellates, like Chlamydomonas possess sexual reproduction, so that, even if no sexual reproduction among Peridineae should exist, they may yet very well have been derived from ancestors which did reproduce sexually and consequently could hybridize. In this respect it would be interesting to know whether Peridineae are haploid or diploid, in the latter case perhaps a pogamic, organisms.

Another objection which has been made against my views, is one, rather based on sentiment than on any other consideration, to wit that it is inconceivable how from a hybrid between two invertebrates a vertebrate could arise. Even if it were, I fail to see how this could be inconceivable to Dr. DENDY, who raised the objection, because he himself sees no difficulty in imagining the origin of a vertebrate from one invertebrate.

The last objection I am aware off, is put interrogatively: „how do you explain the origin of the first diversity?"

This of course is a philosophical question, raised on an assumption, to wit, that at the beginning there was no diversity, a standpoint very akin to the one of creation of the universe out of nothing.

It seems to me that creation out of nothing is quite inconceivable, and certainly outside the pale of science and that the idea that all organisms must have arisen from a single kind of urplasma is a mere survival of the creation-myth which ascribes the origin of all races of mankind, black, red, yellow or white to a single Adam and Eve.

We know of course nothing of the way in which the very simplest forms of life have arisen, and as long as this is the case I see no reason to give any preference to the belief that but one kind of urplasma has arisen above the more general assumption that different kinds of urplasma arose, in other words, that diversity of life 
has existed from the moment that life arose, and here we come to the point where the limit of the influence of hybridization is reached.

All we know of hybridization is connected with the nucleus, with the chromosomes; the cytoplasm is out off its reach.

While I am writing this, I am looking upon the majestic masses of granite in the Yosemite-valley; they have been modified by erosion, by freezing and thawing, by the scorching of the sun and by glacial action, and the marvellous scene upon which $I$ am looking is the result of all these modifying agents. But that imposing scene was, in the last instance, determined by the structural properties of the granite itself; had the rock been of another kind, then the result would have been another too.

An analogon to the granite in lifeless nature, is, it seems to me, the cytoplasm in the living world; it is, I take it, the cytoplasm which determines the nature of the great phyla, it are the chromosomal sets, whose composition changes continuously by repeated hybridization, which have differentiated within these phyla the smaller groups up to the so called species.

Similar views, though not going to the extent here accepted, have been expressed by ConkLIN and LoEB so that I am in good company. It would of course be of the greatest importance to settle the size of the groups possessing the same kind of cytoplasma; up to the present moment, my efforts in this line have been completely frustrated, and the reason, in full accordance with the above surmise, is probably the very great extent of these groups.

Such is also the opinion of palaeontologists. who are more and more inclined to assume that the origin of the great phyla lies very far back.

In his Presidential Address at Edinburgh ScotT states, that in his opinion, the idea that the Gymnosperms descend via the Pteridophytes from ferns, an idea which he once held himself, must be discarded in view of a very much older origin of the seedplants, probably as old as any of the accepted groups of vascular Cryptogams. In connection with this view he cites the opinion of Paul Bertrand, that the Cladoxyleae, a very curious group of plants of upper Devonian strata, have been Phanerogamia. If this view became confirmed, the result would be that the Phanerogamia had come into existence as a special phylum, arisen very 
low down, during a phase when the differentiation between stem and leaf was still in its infancy.

CHurch takes a still more radical view; he puts the origin of the different phyla of plants as far back as the Flagellates, a view which would give special weight to the division of the Cormophytes in Polyciliatae and Biciliatae which I proposed many years ago.

The assumption of original diversity is of course a polyphyletic one and such an assumption seems to me to be best in accor. dance with the present standpoint of palaeontology.

The view here presented of course does not need to assume that every phylum, now existing, has had its own initial cytoplasm, because we know that among lower organisms fusion is not limited to the nuclei but affects the cytoplasm also, so that in a similar way as nuclear hybridisation has been the cause of diverse chromosome sets, cytoplasmic hybridisation may have multiplied the different kinds of cytoplasm, which have - so called spontane. ously - arisen.

All this of course is speculation; I have mentioned it only because I have so frequently been asked to present my views on the ultimate consequences of my theory.

Having done this, I now beg leave to say something about the species-question.

At the Toronto-meeting of this Association BAteson has said; that any day the origin of a species might be discovered. I flattered myself to have shown in the case of Antirrhinum rhinanthoides that a linnean species can arise by hybridisation and I see no reason why such diverse races as are know among poultry, rabbits, dogs etc., which almost certainly owe their origin to hybridisation should not be considered as species. In the Origin (p. 16) DarwiN himself says: "Altogether at least a score of pigeons might be chosen, which; if shown to an ornithologist, and he were told that they were wild birds, would certainly be ranked by him as well defined species. Moreover, I do not believe that any ornithologist would in this case place the English carrier, the short faced tumbler, the runt, the barb, pouter, and fantail in the same genus; more especially as in each of these breeds several truly. inherited sub-breeds, or species, as he would call them, could be shown him." 
Yet, Darwin does not consider them as such, because (p. 18) "hardly any cases have been ascertained with certainty of hybrids from two quite distinct species of animals being perfectly fertile", while the hybrids between all the breeds of the pigeon are perfectly fertile.

I fancy that it is this very reason which prevents BATESON from accepting the evidence of any form obtained artificially as conclusive, in the question of the origin of species; that he also considers mutual sterility as the character par excellence of the species.

This view seems to me untenable; the number of species which produce fertile hybrids is increasing daily, while on the other hand we know of self-sterile plants, whose pollen and eggcells should, if sterility of a cross were a sure indication of specific difference, be considered as specifically distinct.

It seems to me that the belief that species should be sterile with one another is nothing but a survival of the idea that species have been separately created and therefore should not interbreed.

To my way of thinking, the species-concept has ceased to exist since it was proved that evolution had taken place.

Inherent to the species-concept is the doctrine of its immutability, the doctrine that all ancestors of a particular type have been of that very type themselves.

Since this view was proved to be untenable the species-concept should have been abandoned.

The Linnean species, to which BATESON refers, is no element of descent, it is simply a group of morphologically similar, not of genotypically identical, individuals and may be, and in many cases doubtless is, polyphyletic in origin.

'We do not find species in nature, what we observe there are different individuals, not different species. Some of these habitually interbreed, form a pairing community or syngameon and it are these syngameons which we, erroneously, designate as species.

Within these syngameons a certain number of different kinds of chromosomes (certainly greater than the chromosome number characteristic of that syngameon, just as in a house a large number of different kinds of chairs may be present, even if in each room of that house say only four chairs are placed) are present, and their different combinations, or in the case of crossing-over, the different 
combinations of their parts, cause together with modifications the diversity which we observe within that particular syngameon and allow a certain amount of adaptability. This diversity however is limited; it does not transgress the limits of the syngameon in question, it is limited to such diversity as is presented by the different colors of eyes, of hair, or, if one prefers a morphological example, to the different features, or qualities of mind within for instance the syngameon which we call white man.

As long as such a syngameon remains closed, as no pairing with members of another syngameon takes place, all characters considered to be characteristic of that syngameon remain constant: a white woman never bears a negro-child to a white man, and this constancy of the so called essential characters of the syngameon makes taxonomists consider it as a species.

When it opens, when it allows members of another syngameon to enter into it, much larger changes take place, evolution sets in as $f . i$. in the case when Spaniards mixed with Indians and the Mexicans arose, or, again, Spaniards mixed with Malays and Philippino's came in existence.

How far such changes go, depends on the comptability of the chromosomes introduced with those already present in the syngameon and on the degree of difference between these and the latter. As an example of considerable changes so produced I may cite the results of the introduction of chromosomes from the syngameon Antirrhinum glutinosum into that of $A$. majus.

The immediate result of a cross is endless diversity; nature immediately begins to play havoc with this diversity, and this elimination leads to the isolation of different types. In other words nature applies the same principle which man applies in breeding: isolation. In this respect DARWIN is perfectly right: the way in which domestic - races arise is the same as that in which "species" arise in nature. There is however considerable difference: man selects - isolates - with a particular end in view: the adaptation of the organism to his needs, DARwin imagined a way by which nature could do something similar, to wit adapt the organism to its own needs, to the conditions under which it has to live, by a process which led to the survival of the fittest. Against this part of the parallel between selection by man and by nature a good 
deal can be said; it assumes that elimination in nature always or a least in a majority of cases hits the less fit, while the great destruction going on in the egg-stage $f$. $i$. speaks very much against this view.

We shall presently hear of Dr. Tower's experiments on this momentous question, here I will only remark, that the great diversity arising atter a cross and the diminution of that diversity in succeeding generations doubtless shows that elimination takes place, on a considerable scale in nature.

On the principles enunciated, it seems to me, that the peculiar distribution of different closely related birds and plants over a limited area with many natural barriers, such as the Galapagosislands, on which DARwin laid so much stress, is much more easily explained on the assumption that the segregates of a cross have been distributed over these islands, and part of them isolated on each of them, than on the basis of any theory of variability.

I need not dwell any longer on the fact that the groups which taxonomists call species are no units, the experiments of JoRDAN with Draba verna and, notably, the recent ones of MACALlum with Parthenium argentatum show that these are composed, when there are no barriers between their members, of a large number of different forms frequently extending over a vast territory. This is exactly what we would expect to occur, if the group of forms which we are wont to consider as a species, had arisen from a cross, because we know, that if no isolation sets in, the diversity of the $\mathrm{F}_{2}$ of a cross is apt to be maintained to a considerable degree in succeeding generations.

I do not of course, for a moment: mean to say that every species - arisen by hybridization, as all are, if my theory be correct maintains the diversity of the $F_{2}$ generation of the cross to which it owes its birth, as it would do, if the breeding had been promiscuous and all descendants had survived. Every cross in nature has undergone the influence of elimination and therefore none has escaped the isolation of particular segregates, be it because some segregates flowered at different times or because others died, thus isolating the remaining ones, for instance because some were killed by frost or drought and others were not, but I do maintain that if, at the present moment, certain parts of Mexico in which Parthenium 
argentatum grows, were flooded and others remained above water, we would obtain on such islands a similar distribution of closely related Parthenium-species, as we now find in the case of animals and plants on the Galapagos-islands, and I think the Partheniumcase a particularly good one, because Dr. Macallum could show that its forms possess a considerable amount of shrivelled pollen which is, to say the least, a suggestive indication of their hybrid origin.

So it seems to me, that, at the present moment, the most probable view of evolution, is evolution by means of hybridization and this view seems to me so very natural, not only because it is based on that very general property of living matter: sexual reproduction and explains its meaning but also because it brings the origin of diversity in lifeless nature - chemical combination into line with that in living nature: hybridization.

I might stop here, were it not that I have heard it objected that on the basis of my views, which do not admit the existence of mutation, I must assume that the urplasmata contained already all those bearers of the millions of characters now exhibited by living organisms.

This objection of course is again based on the assumption of the existence of organoid gens, an assumption which I consider to be ill-founded.

I certainly do not accept the presence of all present day so called gens in the urplasmata, but if we do not speak of gens hypothetical things - but of potentialities, I do not see any objection against the assumption that all what has been realised was already present in potentia in the urplasmata, because this must evidently have been the case, as otherwise it never could have been realised. Ex nullo nihil fit.

If in the atoms the potentiae to form chemical combinations had not been present, these chemical combinations could never have been formed. 